to support the diagnosis of brucellosis for the agglutination test was persistently negative and the patient, though improving promptly with steroid therapy, failed to improve with prolonged administration of tetracycline.

It was therefore concluded that the patient was suffering from an intrahepatic granulomatous arteriopathy of unknown aetiology. Biopsies of other organs were not performed and hence it was not known whether this was an arteriopathy confined to the hepatic vessels or whether the liver biopsy allowed the opportunity to observe a local manifestation of a generalized disease. There were no clinical features to indicate specific involvement of any other organ but the persistent and unexplained anaemia indicates that the lesion, even if localized, was accompanied by systemic effects.

The prompt response to steroid treatment in this patient suggests, in the absence of any other obvious aetiological factors, a hypersensitivity reaction, though the arterial lesions did not resemble those described as typical of hypersensitivity states (Chure \& Strauss, 1951).

\section{Acknowledgments}

We are indebted to Professor A. C. P. Campbell for his advice and criticism; to Dr E. G. Wade for allowing us to quote the clinical details of this case and to Mr G. Humberstone for taking the photomicrographs.

\section{References}

Churg, J. \& Strauss, L. (1951) Allergic granulomatosis. allergic angiitis and periarteritis nodosa. Amer. J. Path, 27, 277.

Erickson, T.C., Odom, G. \& Stern, K. (1942) Boeck's disease (sarcoid) of the central nervous system. Arch. Neurol. Psychiat. 48, 613.

Meyer, J.S., Foley, J.M. \& Campagna-Pinto, D. (1953) Granulomatous angiitis of the meninges in sarcoidosis. Arch. Neurol. Psychiat. 69, 587.

\title{
Sideropenic anaemia with reticulo-endothelial siderosis in a case of hypernephroma
}

\author{
K. Chatterjee \\ M.R.C.P.(Lond.), M.R.C.P.(Edin.) \\ Medical First Assistant
}

\author{
G. E. MacLellaN
}

Medical Student

St George's Hospital, London, S.W.1

\section{Summary}

A case of sideropenic anaemia with reticuloendothelial siderosis is described. At the time of admission the anaemia was severe and the cause was not apparent. Extensive search had to be made to reveal the neoplasm, a hypernephroma.

\section{Introduction}

Of the various types of anaemias encountered in patients with neoplastic disease, sideropenic anaemia with reticulo-endothelial siderosis is the most interesting and puzzling. According to Cartwright (1966), it is usually mild in degree and not progressive in severity, but when the anaemia is moderately severe the causal neoplasm is almost always obvious. The case reported here presented with severe anaemia long before the underlying neoplasm could be detected.

\section{Case report}

The patient, a man aged 58 , a caterer by profession, was admitted with a 3 months' history of increasing tiredness, generalized weakness and shortness of breath on exertion. He had lost approximately 1 stone of weight in the 6 months preceding admission. He had never had indigestion and his appetite had always been good. The only relevant past history was that he had contracted syphilis about 30 years before.

On examination, he appeared very anaemic, but not jaundiced. The tongue, buccal mucous membranes, nails, palms and soles of the feet appeared pale but otherwise normal. There were no palpable glands or sternal tenderness. The skin and joints were normal. The liver was just palpable, one finger breadth below the right costal margin, smooth and not tender. All the features of a hyperkinetic circulation were present, with moderate tachycardia, slightly raised JVP, hyperdynamic cardiac impulse, flow murmurs in all cardiac areas, wide pulse-pressure, warm hands and digital pulsation. The only other $a b$ normal physical finding was the presence of Argyll Robertson pupils-evidence of neurosyphilis. Capillary fragility test, rectal examination and proctoscopy were normal. 
Investigations. $\mathrm{Hb} 6.9 \mathrm{~g} / 100 \mathrm{ml} \mathrm{(47 \% ),} \mathrm{PCV}$ $28 \%$, MCHC $25 \%$, ESR $47 \mathrm{~mm} / 1 \mathrm{hr}$, WBC $10,000 / \mathrm{mm}^{3}$, differential count normal. Reticulocyte count $2.5 \%$. Platelets normal. Blood film: anisocytosis, poikilocytosis, slight microcytosis and marked hypochromia. Repeated stool examination for occult blood: negative. Urine: no red cells found. Occult blood test negative. Thymol turbidity 0.5 units, SGPT $<5$ units, serum bilirubin $0.3 \mathrm{mg} / 100 \mathrm{ml}$, alkaline phosphatase 30 units (K.A.). Chest X-ray and ECG normal. Blood W.R. +1/160, RCPT +1/40, TPI test positive. CSF: Sugar $60 \mathrm{mg} / 100 \mathrm{ml}$ protein $45 \mathrm{mg} / 100 \mathrm{ml} 25$ WBC $90 \%$ lymphocytes W.R. $+1 / 10$ RPCFT +1/5 Barium meal normal.

A provisional diagnosis of iron-deficiency anaemia was made and he was treated with iron. $\mathrm{He}$ also received a full course of antipsyphilitic treatment. However, bone marrow examination revealed: 'Normoblastic hyperplasia, normal leucopoiesis, with very few giant metamyelocytes, numerous megakaryocytes. Stainable intracellular iron in erythrocyte precursors virtually absent. A large excess of storage iron is present. No malignant cells are seen.'

Further investigations showed: Serum iron $15 \mu \mathrm{g} / 100 \mathrm{ml}$. Total iron binding capacity $156 \mu \mathrm{g} /$ $100 \mathrm{ml}$. Haptoglobin not reduced. Serum $\mathbf{B}_{12}$, $245 \mu \mathrm{g} / \mathrm{ml}$. Serum folate, $0.8 \mu \mathrm{g} / \mathrm{ml}$. ${ }^{59} \mathrm{Fe}$ plasma clearance $15 \mathrm{~min}$-consistent with diagnosis of secondary anaemia.

At this stage the nature of the anaemia was evident and in the absence of chronic infection and rheumatoid arthritis, the presence of an underlying neoplasm - responsible for this anaemia became highly probable. Repeated clinical examinations were unhelpful. Further investigations were carried out as follows:

Barium enema showed multiple diverticula of sigmoid colon. Urine: no Bence-Jones protein detected. Serum proteins $6.3 \mathrm{mg} / 100 \mathrm{ml}$, albu$\min 2 \cdot 1, \alpha_{1}$-globulin 0.8, $\alpha_{2}$-globulin, $1.3 \beta$ globulin, $1.1 \gamma$-globulin, $0.8 \mathrm{mg} / 100 \mathrm{ml}$. Serum calcium $9.5 \mathrm{mg} / 100 \mathrm{ml}$, inorganic phosphate 2.6 $\mathrm{mg} / 100 \mathrm{ml}$, acid phosphatase 1.2 units. Skull $X$-ray and repeat chest $X$-ray normal. Straight $X$-ray abdomen: osteolytic lesion of left transverse process of left lumbar vertebra.

Intravenous pyelography revealed that the left pelvicalyceal system was displaced downwards and the upper pole calyces were displaced and dilated. The appearance was suggestive of renal carcinoma. Selective renal angiography also showed that the upper pole of the left kidney was occupied by a mass of tumour vessels. The appearance was very suggestive of renal tumour.

When the patient was subjected to operation, a large vascular tumour, occupying the upper half of the left kidney and invading along the pedicle, aorta and lumbar vertebrae was found. The tumour could not be removed completely. Histology showed adenocarcinoma of the kidney.

The immediate post-operative period was uneventful. Two weeks after operation the haemoglobin rose to $12.7 \mathrm{~g} / 100 \mathrm{ml}(87 \%)$ and serum iron up to $195 \mu \mathrm{g} / 100 \mathrm{ml}, \mathrm{PCV}$ and MCHC were $39 \%$ and $33 \%$, respectively. He was treated with a course of deep X-ray therapy, but about 4 weeks later his condition deteriorated again due to widespread metastases to the lungs and bones and he ultimately died. Necropsy showed extensive metastases to the lungs, the opposite kidney and to the vertebrae.

\section{Discussion}

In neoplastic disease various types of anaemias may be encountered: myelophthisic anaemia with extensive bone-marrow metastases (Rundles \& Jonson, 1949); true iron deficiency anaemia with low storage iron due to chronic blood loss from an ulcerating tumour; overt haemolytic anaemia (Tedeschi \& Cannicelli, 1948); sideroblastic anaemia - all have been found in tumourbearing hosts. Another well-documented type of anaemia may occur in patients suffering from neoplastic disease. This is characterized by low serum iron, reduced total iron-binding capacity, low saturation of transferrin, normal or slightly increased erythropoiesis in bone marrow and excess of storage iron in the reticulo-endothelial system. As this same type of anaemia may occur in various other disorders like chronic infection, rheumatoid arthritis, rheumatic fever, collagen diseases, fractures and severe tissue injuries, dermatological conditions, etc., it has been variously known as 'chronic simple anaemia', 'anaemia of chronic disorders', 'anaemia of infection' and 'anaemia of malignancy'. But we preferred the term 'sideropenic anaemia with reticulo-endothelial siderosis', as suggested by Cartwright (1966), as it states most of the important diagnostic features of the anaemia.

Severe anaemia is a frequent finding in lymphomas and leukaemias. In carcinomas and other neoplasms, though mild to moderate anaemia is common, severe anaemia to the extent with which our patient presented (haemoglobin $6.9 \mathrm{~g} / 100 \mathrm{ml}$, PCV $28 \%$ and MCHC $25 \%$ ), is not very common. In the series of Shen \& Homburger (1951), out of 193 patients with advanced carcinomas, 116 cases had anaemia and of those only $19 \%$ had haemoglobin below $55 \%$. In the series of Samuels \& Bierman (1956), with normal haemoglobin defined as $12.2 \mathrm{~g} / 100 \mathrm{ml}$, 
two patients with carcinomas had an average haemoglobin of $10.2 \mathrm{~g} / 100 \mathrm{ml}$. In the series of Miller et al. (1956), only $13 \%$ of the patients had PCV between 25 and $29 \%, 2 \%$ between 20 and $24 \%$ and $2 \%$ below $24 \%$. Most of the patients had very advanced carcinoma.

The patient under discussion presented with severe anaemia without apparent cause. and, like others reported in the literature, failed to improve after iron therapy. In these cases, as there is already excess of storage iron, iron administration does not produce any haematological response. However, in some patients with cancer, absence of iron in bone marrow reticuloendothelial cells has been observed and only these patients are likely to improve with iron therapy. Hence it is important to know the state of storage iron in bone marrow before any iron therapy is instituted in patients with neoplastic disease.

It is thought that the degree of reduction of serum iron in neoplastic disease probably depends on the extent of the metastases. In the series of Clark Griffith et al. (1965), very low serum iron was found only in those cases who had widespread metastases. In the case reported here, although the serum iron was only $15 \mu \mathrm{g} /$ $100 \mathrm{ml}$ pre-operative investigations did not show evidence of widespread metastases and on surgical exploration the tumour was found to be large but only invading locally the transverse processes of the lumbar vertebrae. It appears that the degree of reduction of serum iron depends on the total mass of tumour cellswhether wide-spread or contained in a single large tumour.

Although the pathogenesis of this type of anaemia is still not clear, it is known that erythrocyte survival time is reduced and the bone marrow fails to correct the anaemia; there is also a failure of iron-release from reticuloendothelial cells. How neoplasms bring about these changes is not yet clearly understood. But whatever the mechanism might be, it is known that if the underlying disorder is alleviated the anaemia improves and the haematological response is observed. Even incomplete removal of the tumour in this case was followed by a rise of haemoglobin to $87 \%$ and of serum iron to $195 \mu \mathrm{g} / 100 \mathrm{ml}$.

From the large number of communications in the literature, mostly devoted to elucidating the mechanism of this type of anaemia, we were unable to find a case where such a degree of anaemia was the only presenting feature for a long time before the underlying neoplasm could be detected.

The purpose of this communication is to emphasize the fact that when this type of anaemia presents as a diagnostic problem, extensive search for neoplasm should be carried out and is likely to give the answer.

\section{Acknowledgments}

We are grateful to Dr M. I. A. Hunter for his valuable criticism in preparing this paper, to Dr K. C. Carstairs, Haematologist to St George's Hospital, for carrying out the haematological investigations. and to $\mathrm{Dr} \mathrm{S}$. E. Johnson, House Physician to Dr Hunter.

\section{References}

Bainton, D.F. \& Finch, C.A. (1964) Diagnosis of iron deficiency anaemia. Amer.J. Med. 37, 62.

CARTWright, G.E. (1966) Anaemia of chronic disorders. Semin. Hemat. 3, 4.

Clark Griffin, A., Dale, S.C., Wellington, D. \& Ward, V.C. (1965) Serum iron levels in patients with malignant disease. Proc. Soc. exp. Biol. (N.Y.), 118, 741

Friedell, G.H. (1965) Anaemia in cancer. Lancet, i, 356.

HymaN, G.A. (1963) Anaemia in malignant neoplastic disease. J. chron. Dis. 16, 645.

Hyman, G.A., Gelhorn, A. \& Harvey, J.E. (1956) Studies of the anaemia of disseminated malignant neoplastic disease. Blood, 9, 618.

HymaN, G.A. \& HARVeY, J.E. (1955) The pathogenesis of anaemia in patients with carcinoma. Amer. J. med. 350.

Miller, A., Chodes, R.B., Emerson, C.P. \& Ross, J.F. (1956) Studies of the anaemia and iron metabolism in cancer. J. clin. Invest. 35, 1948.

Rundlfs, R.W. \& Jonson, U. (1949) Metastases in bone marrow and myelophthisic anaemia from carcinoma of the prostate. Amer. J. med. Sci. 218, 241.

Samuels, A.J. \& Bierman, H.R. (1956) Anaemia in patients with neoplastic diseases. Calif. Med. 84, 180.

Shen, S.C. \& Homburger, F. (1951) The anaemia of cancer patients and its relation to its metastases to bone marrow. J. Lab. clin. Med. 37, 182

Tedeschi, C.G. \& Carnicelli, T.J. (1948) Manifold manifestations of reticulo-endothelial disease. Arch. Path. 45, 73. 